\section{FRI0292 A MULTI-CENTER, RANDOMIZED, DOUBLE-BLIND, PLACEBO-CONTROLLED, PARALLEL GROUP STUDY TO EVALUATE THE EFFICACY AND SAFETY OF SIRUKUMAB IN THE TREATMENT OF PATIENTS WITH GIANT CELL ARTERITIS}

Wolfgang Schmidt ${ }^{1}$, Bhaskar Dasgupta ${ }^{2}$, Raashid Luqmani ${ }^{3}$, Sebastian Unizony ${ }^{4}$, Zhihong Lai ${ }^{5}$, Regina Kurrasch ${ }^{5}$, Ivana Lazic ${ }^{6}$, Kurt Brown ${ }^{5}$, Ravi Rao ${ }^{7} .{ }^{1}$ Immanuel Krankenhaus Berlin, Berlin, Germany; ${ }^{2}$ Southend University Hospital NHS Foundation, Westcliff-on-Sea, United Kingdom, ${ }^{3}$ University of Oxford, Oxford, United Kingdom; ${ }^{4}$ Massachusetts General Hospital Rheumatology Unit, Harvard Medical School, Boston, United States of America; ${ }^{5}$ GlaxoSmithKline, Collegeville, United States of America; ${ }^{6}$ GlaxoSmithKline, Stevenage, United Kingdom; 7 GlaxoSmithKline, Brentford, United Kingdom

Background: Sirukumab (SIR), a selective, high-affinity human monoclonal antibody to the interleukin-6 (IL-6) cytokine, was under development for giant-cell arteritis (GCA) and other diseases.

Objectives: To evaluate the efficacy and safety of sirukumab (SIR) in subjects with GCA.

Methods: This 2-part phase 3 study enrolled subjects with active GCA (NCT02531633). Subjects were randomized in a 3:3:2:2:2 ratio to one of 5 treatment arms: SIR $100 \mathrm{mg} \mathrm{SC}$ q2w + 6-mo prednisone taper (SIR100+6mo), SIR $100 \mathrm{mg} \mathrm{SC}$ q2w + 3-mo prednisone taper (SIR100 $+3 \mathrm{mo}$ ), SIR $50 \mathrm{mg} \mathrm{SC} q 4 \mathrm{w}+6-\mathrm{mo}$ prednisone taper (SIR50+6mo), placebo (PBO) SC q2w + 6-mo prednisone taper (PBO+6mo), PBO SC q2w + 12-mo prednisone taper $(\mathrm{PBO}+12 \mathrm{mo})$, for 52-week treatment(Part $\mathrm{A})$. Following completion of Part $A$, subjects could enroll into the study extension with option for open label SIR treatment (Part B). The primary endpoint was the proportion of subjects in sustained remission at Week 52. Secondary endpoints included sustained remission over time, disease flare, and safety. As a result of the early study termination due to administrative reasons, the revised primary endpoint intent-to-treat analysis (revised ITT, $\mathrm{N}=55$ ) included only subjects who received at least 1 dose of the SC investigational product and had completed 52 weeks $(\mathrm{N}=28)$ or had discontinued the study prior to study termination $(n=27)$.

Results: A total of 161 of planned 204 subjects were randomized (mean age 69.6 years, $77.0 \%$ female, $98.1 \%$ white, $55.9 \%$ with new-onset disease). Baseline prednisone dose was $\geq 30 \mathrm{mg} /$ day in $50.9 \%$ of subjects. The proportions of subjects with disease flares from Week $2(\mathrm{~N}=155)$ to Week 52 were lower in the SIR $100+6 \mathrm{mo}(18.4 \%)$, SIR $100+3 \mathrm{mo}(28.2 \%)$ and SIR50+6mo (30.8\%) arms compared to the PBO+6mo (40\%) and $\mathrm{PBO}+12 \mathrm{mo}(37 \%)$ arms.

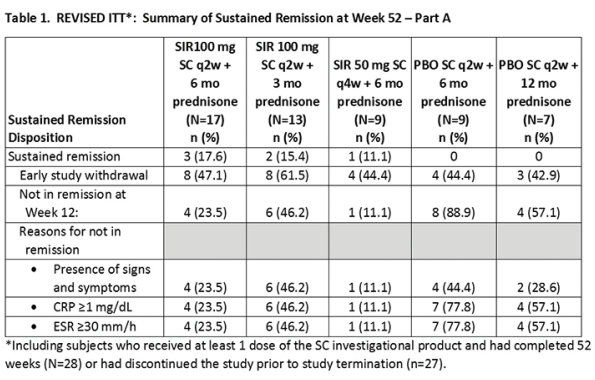

In Part A, 152 subjects (94.4\%) experienced at least 1 treatment-emergent adverse event (TEAE), with similar proportions of subjects across the treatment arms. The most common TEAE's (>10\% total subjects) were headache, arthralgia, back pain, cough, upper respiratory tract infection. Treatment-emergent serious adverse events (TESAE) were reported for 31 subjects with similar incidence across all treatment arms. There were no reported deaths, GI perforations or TB activation. Infections and infestations were the most common TESAE, 6 subjects, with no clear difference between SIR and PBO. Two subjects had new onset GCArelated vision loss $(\operatorname{SIR} 100+3 \mathrm{mo}, \mathrm{n}=1 ; \mathrm{SIR} 50+6 \mathrm{mo}, \mathrm{n}=1)$. There were 3 subjects with adjudicated major adverse cardiovascular events (SIR100 $+3 \mathrm{mo}, \mathrm{n}=2$; $\mathrm{PBO}+12 \mathrm{mo}, \mathrm{n}=1$ ). $\mathrm{NCl}$ CTCAE Grade 3 or 4 laboratory abnormalities of increased ALT, bilirubin, cholesterol, triglycerides and decreased leukocytes, neutrophils, and platelets occurred only in SIR treatment arms $(0.6$ to $2.5 \%$ of total subjects)

Conclusion: As a result of early study termination, only a few subjects, all in SIR treatment arms, achieved the primary endpoint of sustained remission at Week 52. The proportion of subjects with flares from Week 2 - 52 were higher in the PBO arms compared to SIR arms. The overall safety was consistent with the known SIR safety profile.

Study funded by GSK

Disclosure of Interests: Wolfgang Schmidt Grant/research support from: GSK, Roche, Novartis, Sanofi, Consultant for: GSK, Roche, Novartis, Sanofi, Bhaskar Dasgupta Consultant for: Roche, GSK, Sanofi, BMS, Abbvie, Speakers bureau: Roche, Raashid Luqmani Grant/research support from: Roche, Vifor and GSK, Sebastian Unizony Grant/research sup port from: F. Hoffmann-La Roche, Genentech, Consultant for: Kiniksa, Sanofi, GSK, Zhinong Lai Shareholder of: GSK, Employee of: GSK, Regina Kurrasch Shareholder of: GSK, Employee of: GSK, Ivana Lazic Shareholder of: GSK, Employee of: GSK, Kurt Brown Shareholder of: GSK, Employee of: GSK, Ravi Rao Shareholder of: GSK, Employee of GSK

DOI: 10.1136/annrheumdis-2019-eular.5846

\section{FRI0293 FACTORS ASSOCIATED WITH FIRST-YEAR AND OVERALL MORTALITY IN ANCA ASSOCIATED VASCULITIS; PATIENTS WITH RENAL LIMITED VASCULITIS MAKES NO BETTER THAN MICROSCOPIC POLYANGIITIS}

Onay Gercik ${ }^{1}$, Zeki Soypacaci ${ }^{2}$, Fulya Çakalağaoğlu ${ }^{3}$, Gokhan Kabadayi ${ }^{1}$, Idil Kurut ${ }^{1}$, Dilek Solmaz ${ }^{1}$, Servet Akar'. ${ }^{1}$ Izmir Katip Celebi University, Faculty of Medicine, Rheumatology, Izmir, Turkey; ${ }^{2}$ Izmir Katip Celebi University, Faculty of Medicine, Nephrology, izmir, Turkey, ${ }^{3}$ Izmir Katip Celebi University, Izmir Ataturk Education and Reseach Hospital, Pathology, Izmir, Turkey

Background: Overall mortality in ANCA-associated vasculitis (AAV) over the last two decades has been reported to be decreasing with the use of immunosuppressive therapies. However, mortality rates remain high and most of the deaths occur in the first year after diagnosis despite treatment.

Objectives: In this study, we aimed to determine the prevalence of mortality in our AAV patients and to investigate the factors that may be associated with first-year and overall mortality.

Methods: Patients followed up in one center with the diagnosis of AAV were included in the study. Diagnostic subgroups were; granulomatosis with polyangiitis (GPA), microscopic polyangiitis (MPA), eosinophilic granulomatosis with polyangiitis (EGPA), and renal-limited vasculitis (RLV). The clinical and demographic characteristics of the patients were collected retrospectively. Factors predictive of mortality were evaluated by KaplanMeier method and the Cox proportional hazard model.

Results: In total 104 (45 [43\%] female and mean age $54.9 \pm 15.4$ years) AAV patients (51 GPA; 25 MPA; 27 RLV and 1 EGPA) were included in the analysis. ANCA positivity was detected in 81 (77.9\%) patients with IIF and/or ELISA. ESRD had developed in 31 (32.3\%) of AAV patients and in $37.8 \%$ of patients with renal involvement. Mortality rate was $14.4 \%$ in the first year after diagnosis and $27.9 \%$ during a median follow-up period of 1289 (5-5804) days. The age at diagnosis was the only significant predictor of first-year mortality $(\mathrm{p}=0.006)$. Univariate analysis revealed that overall mortality was associated with AAV subgroups $(p=$ 0.035 ), renal $(p=0.046)$ (figure) and, ENT (ear-throat) involvement ( $p=$ $0.025)$, ESRD $(p=0.025)$ and hemodialysis at the time of diagnosis ( $p$ $=0.040$ ). However Cox regression analysis showed age at diagnosis as the only significant predictor also of the overall mortality $(P=0,001)$.

Conclusion: Our findings suggest that there could be some survival differences between AAV subgroups and patients with or without renal and ENT involvement. However, the age at diagnosis seems to be the only significant predictor of first-year and overall mortality in our AAV patients. 
a

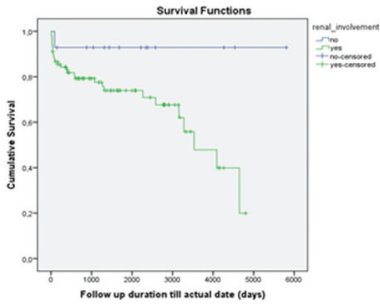

b

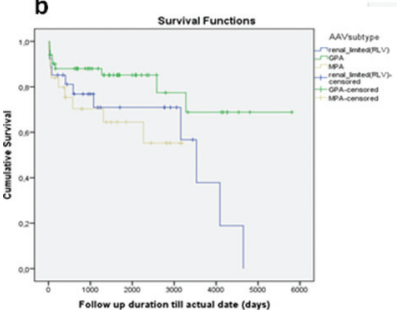

Figure. The results of the Kaplan-Meier analysis. Overall mortality was significantly associated with renal involvement (a) and AAV subgroups (b).

*AAV: ANCA-Associated Vasculitis; GPA: Granulomatosis with PolyAngiitis; MPA: Microscopic PolyAngiitis; RLV: Renal Limited Vasculitis

Disclosure of Interests: Onay Gercik: None declared, Zeki Soypacaci: None declared, Fulya Çakalağaoğlu: None declared, Gokhan Kabadayi: None declared, Idil Kurut: None declared, Dilek Solmaz: None declared, Servet Akar Grant/research support from: MSD, Abbvie, Roche, UCB, Novartis, Pfizer, Amgen, Consultant for: MSD, Abbvie, Roche, UCB, Novartis, Pfizer, Amgen, Speakers bureau: Pfizer

DOI: 10.1136/annrheumdis-2019-eular.4178

\section{FRI0294 CHEMOTHERAPY AND G-CSF INDUCED LARGE VESSEL VASCULITIS AND CAROTIDYNIA - SIX PATIENT CASES AND A SYSTEMATIC LITERATURE REVIEW}

Kirsi Taimen ${ }^{1,1}$, Samu Heino ${ }^{2}$, la Kohonen ${ }^{3}$, Heikki Relas ${ }^{4}$, Riikka Huovinen ${ }^{5}$, Arno Hänninen ${ }^{6}$, Laura Pirilä ${ }^{1} .{ }^{1}$ Turku University Hospital, Rheumatology and Clinical Immunology, Turku, Finland; ${ }^{2}$ University of Turku, Medicine, Turku, Finland; ${ }^{3}$ Turku University Hospital, Radiology, Turku, Finland; ${ }^{4}$ Helsinki University Hospital, Rheumatology, Turku, Finland; ${ }^{5}$ Turku University Hospital, Oncology, Turku, Finland; ${ }^{6}$ University of Turku, Medical microbiology and immunology, Turku, Finland

Background: Large vessel vasculitis (LVV) and neutropenic infection in patients receiving chemotherapy present similar clinical symptoms with fever and high inflammation parameters. Infection is more frequent but LVV should be kept in mind as differential diagnosis. LVV is a serious condition which may lead to vessel wall damage. Published few case reports and adverse event reports suggest causal association between LVV and use of granulocyte colony-stimulating factor (G-CSF) and/or chemotherapy (1).

Objectives: To evaluate the rare connection of LVV and anticancer therapy by describing our six patient cases and a systematic review of the literature.

Methods: Between 2016-2018 we identified six patients with probable drug induced LVV associated with chemotherapy and G-CSF. All patients had breast cancer. Systematic literature review was performed according to PRISMA guidelines using comprehensive search terms for breast cancer, chemotherapy, LVV and G-CSF.

Results: In our case series, 5/6 patients developed LVV symptoms within two weeks after administration of docetaxel and G-CSF. Vasculitis symptoms disappeared after drug cessation or drug change.

Literature search identified 16 published case reports with association of LVV and chemotherapy fulfilling our study criteria. Altogether 22 cases were analyzed. Mean age was 59 years (range 40-77 years). In 14/22 cases data from G-CSF administration was available. Time delay from drug administration to LVV symptoms was average 10 days (range 1-42 days) with G-CSF and median 12 days (range 2-310 days) with chemotherapy. Most prevalent cancer types were breast cancer (8/22), hematological malignancies (7/22) and lung cancer (3/22). Most common clinical LVV symptom were fever (18/22), neck pain (11/22) and chest pain (8/22). Diagnosis was confirmed with imaging studies showing vasculitis in various large vessels in upper body. Notably, four cases had vascular inflammation only in carotid region and this was recognized by radiologist as carotidynia/transient perivascular inflammation of the carotid artery (TIPIC) syndrome.

Conclusion: Large vessel vasculitis is a possible serious rare adverse event associated with chemotherapy (possibly docetaxel) and G-CSF. Since signs and symptoms are non-specific, we assume this condition is underdiagnosed and should be kept in mind when treating oncological patients. Successful management requires early identification and cessation of the drug. When diagnosed and treated properly, the recovery is usually fast.

\section{REFERENCE:}

[1] Lardieri, A., McCulley, L., Christopher Jones, S. \& Woronow, D. Granulocyte colony-stimulating factors and aortitis: A rare adverse event. Am. J. Hematol. 93, E333-E336 (2018).

Disclosure of Interests: Kirsi Taimen Speakers bureau: Pfizer, Novartis, Abbvie, Roche (lectures), Samu Heino: None declared, la Kohonen: None declared, Heikki Relas Speakers bureau: Pfizer, Riikka Huovinen Consultant for: Roche, Amgen, Novartis, Pfizer, Speakers bureau: Roche, Amgen, Novartis, Pfizer, Arno Hänninen Speakers bureau: Roche, Laura Pirilä Consultant for: Abbvie, Novartis, Eli Lilly, MSD Finland, Pfizer, UCB, Roche, Jansen- Cilag, Sandoz, Speakers bureau: Pfizer, DOI: 10.1136/annrheumdis-2019-eular.5009

\section{FRI0295 EVALUATION OF CLINICAL CHARACTERISTICS IN BEHCET SYNDROME BY GENDER AND AGE; A SINGLE CENTER EXPERIENCE WITH 665 PATIENTS}

Murat Torgutalp, Serdar Sezer, Müçteba Enes Yayla, Ayse Bahar Kelesoglu Dincer, Emine Gözde Aydemir Gülöksüz, Didem Sahin Eroglu, Tahsin Murat Turgay, Gülay Kınıklı, Askin Ates. Ankara University Faculty of Medicine, Rheumatology, Ankara, Turkey

Background: To evaluate clinical characteristics according to age and gender in patients with Behcet's Syndrome (BS).

Objectives: BS is a systemic vasculitis that affects mucosa, skin, joint, eye, vessels, gastrointestinal system, and central nervous system. The disease characterizes by relapses and remissions, and it is known that prognosis is worse in young males. The aim of this study was to reinvestigate the relationship between the clinical features of BS according to gender and age.

Methods: The data of 665 patients (282 male, 383 female), diagnosed as BS according to the ISG-1990 Behçet's Disease classification criteria were retrospectively evaluated.

Results: All patients had oral aphthous (OA) ulcers (100\%). Eighty-five percent of patients had a genital ulcer (GU), 56.5\% had erythema nodosum (EN), 65.9\% had papulopustular lesions (PPL), 32.6\% had ocular involvement, $49.3 \%$ had joint involvement, and $21.7 \%$ vascular involvement, and $4.8 \%$ had neurobehcet. The incidence rates of PPL, ocular involvement, and vascular involvement were significantly higher in males ( $p<0.001, p=0.004$ and $p<0.001$, respectively). GU, joint involvement, headache, and pathergy positivity were more common in women $(p=$ $0.006, p<0.001, p<0.001$ and $p<0.001$, respectively). Table 1 shows the comparison of the clinical features according to gender. When we compare the mean age of the patients according to the presence or absence of clinical findings; patients with GU, EN, and vascular involvement were found to be younger than those without $(p=0.006, p=$ 0.025 and $p=0.007$, respectively) (Table-2).

Conclusion: Clinical features of BS may vary according to age and gender. Variations can be observed depending on the size of the population, the center where the study is conducted, and the selected-criteria for inclusion. In our study, PPL, ocular involvement and vascular involvement were more frequent in men, whereas GU, joint involvement, headache, and pathergy positivity were more common in women. In addition, GU, EN, and vascular involvement were related to younger ages. Our results were compatible with the BS literature.

\section{REFERENCES}

None 